the induction of p450 enzymes by carbamazepine. This leads to a lowering of serum tricyclic concentrations when tricyclics are given with carbamazepine, thus reducing their antidepressant action (Leinonen et al, 1991; Preskorn, 1993). Such interactions altering the serum concentrations of tricyclic antidepressants are unlikely to be adequately appreciated until the measurement of serum tricyclic antidepressant concentrations becomes routine clinical practice, especially for cases that are difficult to treat.

Leinonen, S. A., Limsunde, P., Laukranen, V., et al (1991) Effects of carbamazapine on serum antidepressant concentrations in psychiatric patients. Journal of Clinical Pharmacology, 11, 313-318.

Preskorn, S. H. (1993) Pharmacokinetics of antidepressants: why and how they are relevant to treatment. Journal of Clinical Psychiatry, 54 (Suppl. 9), 14-34.

TAYLOR, D. \& LADER, M. (1996) Cytochromes and psychotropic drug interactions. British Journal of Psychiatry, 168, 529-532.

Geoffrey Knight National Unit for

R. J. BowSKILL P. K. BRIDGES

Affective Disorders

Maudsley Hospital

London SE5 8AZ

\section{Cross-cultural studies}

SIR: The success of the Bradford Somatic Inventory (BSI) in identifying minor psychiatric morbidity in a rural Pakistani district underlines the value of instruments which have been validated in ways that are language and culture sensitive (Mumford et al, 1996). The identification of these psychiatric cases however recalls the argument of the legitimacy of imposing Western psychiatric diagnoses in non-Western societies (Kleinman, 1977). In stating that to the casual Western visitor life in this remote district appears idyllic and contented suggests that the authors, while good intentioned, may have fallen into the trap of the ethnic psychiatrists of the past, who sought out psychopathology in exotic places while reinforcing colonial and neocolonial attitudes and behaviour (Bhugra, 1993). It is important to recognise that translation (as in establishing a diagnostic index in one setting and then translating it so that it can be used in another) does not ensure congruity of sociocultural perspectives. Translation only ensures that there is an approximate equivalence between categories whose origins lie in very different social contexts (Skultans, 1993).

It is therefore unfortunate that there is no account of how the villagers themselves interpret and articulate their distress as psychiatry itself is a Western construct and imposes its own sociocultural parameters when observations are made on its behalf. In addition, the lack of information about physical illness is a hindrance to the accurate interpretation of the findings since the correlation of deprivation with both physical and psychiatric morbidity is well recognised and the diagnosis of any psychiatric illness must be related to the presence of physical illness.

There is undoubted value in cross-cultural psychiatric research as mass migration is creating increasingly multicultural Western societies. However, when psychiatry co-opts non-Western experience in ways that would allow the distress that is derived from that experience to be interpreted and categorised in Western terms, the native interpretations are often undermined. What is also lost is the capacity to incorporate this perspective into Western formulations so that the delivery of care in multicultural Western societies can be more relevant and effective. A goal that continues to be elusive.

BhugrA, D. (1993) Cross-cultural psychiatry. Why? Where? How? International Review of Psychiatry, 5, 123-124.

KLetnman, A. (1977) Depression, somatization and the 'new cross-cultural psychiatry'. Social Science and Medicine, 11, 3-10. MuMforD, D. M., NAZIR, M., JiLANI, F., et al (1996) Stress and psychiatric disorder in the Hindu Kush. A community survey of mountain villages in Chitral, Pakistan. British Journal of Psychiatry, 168, 299-307.

Sxultans, V. (1993) The case of cross-cultural psychiatry: squaring the circle? International Review of Psychiatry, 5, 125-128.

Maudsley Hospital

G. HutCHINSON

\section{London SE5 8AZ}

\section{Lithium and weight gain}

SIR: Previous studies show that weight increases during the first two years of lithium therapy and then stabilises, that a quarter of patients do not put on weight at any stage (Vestergaard et $a l, 1990$ ) and that a quarter become obese (Chen \& Silverston, 1990). Consequently the BNF mentions weight gain as a problem. This was investigated in a lithium clinic where in 17 years no patient had dropped out because of weight gain.

Forty-two unipolar and bipolar patients on lithium for 1-25 years with or without concomitant antidepressants or neuroleptics were weighed in shoeless light attire and their height measured. Using the same balance arm weighing machine and measure, controls similarly attired from the same locality and not suffering from any known 